\title{
Baudrillard e a Pós-Modernidade
}

\author{
Candido Mendes
}

\section{REPRESENTAÇÃO E NOVA ONTOLOGIA}

$\mathrm{O}$

s paradoxos de Jean Baudrillard querem responder a situações-limite da reflexão contemporânea. Passam pelas frases feitas para devolver-lhes o sentido. Jean é o pensador do pós-moderno, no que o conceito exprime de verdadeira instância crítica na "vida do espírito" de nosso tempo, e sua reflexão vai a dimensões comparáveis à de Habermas ou à de Derrida, em um pressentir as novas condições ontológicas em que não deparamos, apenas, as desconfianças do cógito, mas da realidade bateada pela linguagem, ou pela reificação da consciência ou pelo advento implacável do simulacro.

Seu enterro contou com mais de meio milhar de assistentes, e é difícil, na imprensa européia, encontrar, desde a morte de Sartre, um impacto continuado de análises e reperguntas, postuladas pela sedução subversiva do pensamento ou das condições de sua fuga a qualquer reducionismo. Baudrillard levou ao extremo de um ethos o cancelamento da própria idéia de morte, no seu "paroxismo da diferença", a desimpedir o seu pensamento de toda a contrafação do absoluto sem dédalos, nem álibis ou negociação de permanências.

O discurso do pensador impôs-se no nível ontológico de ruptura radical, ou de contraponto, sem conceder qualquer moto-contínuo à dialé-

DADOS - Revista de Ciências Sociais, Rio de Janeiro, Vol. 50, no 1, 2007, pp. 5 a 9. 
tica. Afez-se a última fidelidade ao seu tempo, como espanto, na sagacidade metodológica dos reinícios, em que a morte se descarta até como detalhe, em um absoluto em stacattos. O paradoxo neutraliza qualquer paroxismo. Jean instala no ethos de hoje o legítimo atemporal deste questionamento, passado à troca simbólica, tão diferente do "ser-para-a-morte" heideggeriano ou da radical assunção do insuportável do fim que nos deu François Lyotard. Baudrillard não contrapôs, apenas, a consciência-limite da contingência à sua banalização, mas o seu próprio relevo como evento, descartando-o, enfim, como a cinza do seu cigarro. Inseria-se em um cosmos, em toda a radicalidade de seu despegue, no jogo das subversões, em que se inverte a própria relação do real pelo simulacro, o ético pela transparência do mal e a perseverança no tempo pela ilusão do fim. É um universo sem fugas o que demarcou Jean Baudrillard, tendo levado às últimas conseqüências a negociação da trégua simbólica com a morte, rendendo-se à "troca impossível". A presença do pensamento baudrillardiano nasce toda da hiperconsciência da própria estase em aguilhão, sem concessões, no pós-moderno deste seu "ser no mundo".

\section{DIALÉTICA E FATALIDADE FRAGMENTÁRIA DO CONHECIMENTO}

O mais de meio século peregrino da sua reflexão define toda uma metodologia deste encontro da subjetividade esquiva, no seu ofício epistemológico, que denota, como define, a tecer o fio do próximo passo. Corta-o a sideração, e sabe que o ilusório não se opõe à realidade. O caminho é o de buscar o outro nas suas figuras, e é possível o crime perfeito, tanto se dê conta dos perigos de Ulisses e suas sereias reducionistas, qual seja, o de atravessar as tentações do pensamento radical, as estratégias fatais e os paraísos artificiais do pensamento.

Jean fez da obra o que se pediria ao homem, e o tratado foi logo ao texto baudrillardiano, só comparável, nessas décadas, ao de Foucault. A tessitura não é por sua vez a do ensaio nem da memória de Montaigne, nem do aforismo pascaliano, mas deste innuendo inédito, no qual a imagem e a ratio trocam os seus eidos na sideração. E a estase é esse tempo que pede epoches ou suspensões, e esconde o discurso em "mots de passe", ou só pode anunciar-se "de um fragmento ao outro".

Seu remate exige - repete-o nas "fundações do tempo" - a ruptura pela ascese da provocação e do choque. Pede que se esqueça Artaud, como Foucault, na purga das exclusões e dos álibis das obras-primas, como 
estratagemas para elidir o mal na sua "última exuberância". E é, ao mesmo tempo, todo este cuidado epistêmico pós-cógito, nas suas adequações, que marca a larga trajetória dos livros de Jean, a procurar as novas cauções da realidade pelas suas "reverberações", ou seus espelhos, ou "divinizações". Do contemplar do museu "Beaubourg" ao contemplar dos préstitos do mundo da produção, situa a ribalta perversa para toda mudança real a que aspire uma esquerda em nossos dias. Se creditamos a Débord o conceito-chave de espetáculo, Baudrillard o demarcou antes, emprestando-lhe uma filosofia para além do lampejo da descoberta, com vistas aos vis-à-vis de percepção do real.

\section{DA REIFICAÇÃO AO SIMULACRO}

O simulacro invade, por inteiro, a subjetividade, com a força de seu foro, para ficar. E sua teoria implica a completa erradicação do evento nesta literal instalação da nova natureza da realidade, que já perdeu seus próprios marcadores de volta, calcinando a utopia e pedindo um novo pacto de lucidez, só possível como o da custosa e difícil inteligência do mal. Baudrillard emprestou a todo este itinerário interior um senso de remate no "auto-da-fé" explícito, de 2004, do profissionalismo voyeurístico, e dos infernos lustrais. Jean rematou a reflexão das intuições pioneiras e fundadoras sobre o consumismo e o fetiche do objeto nas obras seminais de há uma trintena, que exprimiam, nos seus títulos geminados, a busca de um fato social total: o Sistema de Objetos e a Sociedade de Consumo. A brecha para a pós-modernidade já se anunciava em um ensaio sobre a "economia política do sinal". E é o Jean dos estudos mais rigorosos na sociologia interdisciplinar que o perfilha como tese, e leva à sua láurea no exame por Barthes, Bourdieu e Lefebvre. É ainda pela consagração convencional que se transforma em professor-chave de 1968, na Sorbonne de Nanterre, onde encontrará Marine, na clássica atração de professor-aluna, a terminar em casamento. Baudrillard, tão em contraste com o cerne do pensamento francês florescido do segundo após guerra, refletia o pensamento alemão pós-fenomenológico, no leitorado em Tübingen, e não sem razão traduziu Hölderlin, confluindo na mesma admiração de Heidegger e no entendimento ontológico da poesia como "a fundação do ser pela palavra".

É com todo o repertório de Husserl e Lukács que o Sistema de Objetos se transforma em um desvelamento sem volta da realidade em construção pela civilização midiática, pelo rapto subliminal do imaginário contemporâneo. 


\section{O DISCURSO DO PARADOXO METÓDICO}

A viagem canônica e meticulosa aos Estados Unidos - Colorado, La Jolla, Los Angeles, Santa Bárbara, Montana, Las Vegas, Nova Iorque em vários ciclos universitários quer-se, logo, cauterizada de todo imediatismo: Cool Memories, tal como a transcender todo voyeurismo pelo profissionalismo do insight, trabalhado pela longa espera.

É em 1981 que Jean ganha, no Japão, a máquina fotográfica para a disciplina do novo imaginário que intuíra, uma trintena antes, pela freqüentação do surrealismo dos anos 1930. Não é Breton, mas seu professor de filosofia em Reim, Emmanuel Peillet, que lhe permite o choque da pataphysique, em vinheta dos mais rigorosos no discernimento do real frente a seu recomeçar. Na fidelidade crítica a esta escola de pensamento recebeu o título de "satrapa transcendental", ao lado de dois profetas deste mundo, de após a grande entente lingüística e a descanonização derradeira do surreal, Umberto Eco e Arrabal.

A ascese da busca baudrillardiana, garantida sempre pelo alerta de seus paradoxos, refinou-se pelas fotografias, no controle dos seus simulacros. Criava uma via paralela entre os textos e as exposições, no remeter-se, ainda, às transgressões da proposta da pataphysique feitas de simetrias tão escondidas quanto opulentas, de um recado para além do óbvio, em que o flagrante já se faz de dentro da caverna platônica, e o inefável acutila o clique, para surpreender a primeira inocência, o flagrante do simulacro.

Jean Baudrillard nos deu o ingrediente antológico para ir adiante do espetáculo como chão peremptório desta transgressão do real. Propôs-se a remetê-la a uma metafísica emergente, em eixos não-euclidianos, e na transposição da velha adequatio, em nova remissão entre o subjetivo e o objetivo, descolado do primeiro espelho. O 11 de setembro emprestaria um tom apocalíptico a esta aceleração dos dois vetores, em que as dimensões ainda cartesianas do real se atropelariam na pós-modernidade. A reificação da consciência chega ao ícone, ou ao reducionismo extremo, adensado sobre toda a transparência das representações da realidade. A expropriação do evento extirpa o homem de todo o seu contexto cultural, neste tempo de preempção, assegurado pelas hegemonias e seus scripts de futuro. Devemos a Jean Baudrillard a profecia que denunciou o excesso de recado, no impacto na queda das torres, quando a metáfora se apropria de toda a nova realidade in fieri. 


\section{AS HEGEMONIAS SEM ESPELHO}

A simetria da figuração, na queda do World Trade Center, é a de anulação de qualquer espelho, quando a "civilização do medo" que inaugura é a do abate do outro, na ronda sem face do terrorismo. Este gestual cego só pode ser o da violência irrecorrível, como o protesto à expropriação definitiva das subjetividades frente ao mundo hegemônico da razão, dos jogos feitos e terminais da sua dinâmica de progresso.

Baudrillard compartilhou com Habermas e Derrida o diálogo limite deste debate ocidental diante do espetáculo apocalíptico da afirmação das diferenças coletivas ante as terraplanagens globalizadoras. Mas se deu conta, ao mesmo tempo, da nova etapa em que, em um quase simultaneísmo inédito no processo histórico, estas subjetividades, por uma vez, eram expropriadas pelos seus simulacros. Voltamos ao primeiro Baudrillard para a salvaguarda instintiva do imaginário, no que o surrealismo já lhe alertara para esta vitimização então incipiente pelo maquinário do ver o mundo. Não temos paralelo, neste pós-moderno de que plantou as paliçadas uma por uma, de obra em que a beleza dos títulos na multiplicidade dos seus sinais antecipe a percepção ainda de um "que fazer", ou a consciência de seu presságio ganhe a perfeição de uma arte prematuramente perdida.

No quadro dessas transparências levitadas, em uma segunda natureza da realidade, como se define o vis-à-vis do bem e do mal, ou se define para sua inteligência o perseguido pacto de lucidez? E até onde, no dito crime perfeito da pós-modernidade, é o rapto sem volta da diferença que envolve uma ruptura sem práxis, a cravar, ainda, os objetos singulares, a ler-se, ainda, o "espírito do terrorismo" resgatável ao "power inferno"? Como encontrar o gume do paradoxismo limite e fundador? $\mathrm{Ou}$, de fato, a nova violência do mundo descamba no subliminal sem saída de uma pós-modernidade que só comporta os exilados do diálogo? 